RESEARCH PAPER

\title{
Environmental tobacco smoke exposure in public places of European cities
}

\author{
M Nebot, M J López, G Gorini, M Neuberger, S Axelsson, M Pilali, C Fonseca, K Abdennbi, \\ A Hackshaw, H Moshammer, A M Laurent, J Salles, M Georgouli, M C Fondelli, E Serrahima, \\ F Centrich, S K Hammond
}

Tobacco Control 2005;14:60-63. doi: 10.1136/tc.2004.008581

See end of article for authors' affiliations

Correspondence to: Maria José López, Public Health Agency, Barcelona, Spain; milopez@aspb.es

Received 20 April 2004 Accepted 25 August 2004

\begin{abstract}
Background: Exposure to environmental tobacco smoke (ETS) has important public health implications. The results of the first European multi-centre study that measured ETS exposure in a range of public places (transport, educational settings, and leisure facilities such as bars and restaurants) are presented.

Method: Nicotine vapour phase was measured using ETS passive samplers containing a filter treated with sodium bisulfate.

Results: Bars and discos are the places with the highest concentrations of nicotine from ETS, median ranging from 19 to $122 \mu \mathrm{g} / \mathrm{m}^{3}$. Restaurants had the next highest values. Concentrations of nicotine generally range from $0.1-5 \mu \mathrm{g} / \mathrm{m}^{3}$ in airports, and from $0.5-10 \mu \mathrm{g} / \mathrm{m}^{3}$ in train stations. Nicotine was also found in schools and universities, yet schools tended to have the lowest concentrations compared to all the other public places sampled. In hospitals levels were generally below $5 \mu \mathrm{g} / \mathrm{m}^{3}$.

Conclusions: Although there is some variability between cities, this study shows that tobacco smoke is present in most of the studied public places. The study also showed that in areas where smoking is prohibited, concentrations of nicotine are lower than in areas where smoking is allowed but they are not zero. The results of this study indicate that policies should be implemented that would effectively reduce levels of tobacco smoke in public areas.
\end{abstract}

$\mathrm{E}$ xposure to environmental tobacco smoke (ETS) has important public health implications. It has been classified as a lung carcinogen ${ }^{1}$ and has been shown to have adverse health effects on adults and children, including heart disease and respiratory disorders. ${ }^{2-10}$ ETS exposure has been measured by different methods such as questionnaires (based on self reported exposure) and by measuring markers of ETS, namely substances found in tobacco smoke (such as nicotine) in bodily fluids (urine, blood, and saliva) or in the air. Markers can give an objective measurement of ETS exposure. Measuring airborne markers can indicate the average level in an environment and is easier to obtain than collecting biological samples. Nicotine has been used in more studies than any other compound, ${ }^{11}$ because tobacco smoke is the only source of nicotine, and also because nicotine is one of the major constituents of cigarette emissions. Also, different brands of cigarettes emit similar amounts of nicotine and laboratory analysis is simple, sensitive, and relatively inexpensive.

Several studies have measured the nicotine concentration in indoor air, ${ }^{12-16}$ mainly in the USA. In Europe, one study carried out measurements of nicotine and others markers in different countries, ${ }^{17-22}$ using personal monitors, but this study might have underestimated the extent of ETS exposure. $^{23}$ We present the results of the first European multi-centre study that measured ETS exposure in a range of public places including transport, educational settings, and leisure facilities such as bars and restaurants. The main objective was to raise awareness of the problem of ETS exposure and to prompt moves to eliminate it.

\section{METHOD}

The study was carried out from October 2001 to October 2002 as part of the Europe Against Cancer initiative. Seven European cities were involved: Vienna (Austria), Paris (France), Athens (Greece), Florence (Italy), Oporto (Portugal), Barcelona (Spain), and Örebro (Sweden).
Nicotine vapour phase was measured using ETS passive samplers, which comprise a plastic cassette (with a windscreen in one side), containing a filter treated with sodium bisulfate that has a diameter of $37 \mathrm{~mm}$. The samplers were placed for a period ranging from four hours to two weeks in the following public places: airports, train stations, schools, universities, hospitals, restaurants, and discos. As a rule, settings were sampled at random when a sampling universe list was available and no other selection criteria prevailed. In Vienna some places known to have high exposure were included. One airport and one train station were sampled in

Table 1 Public places sampled, smoking policy, and sampling time

\begin{tabular}{|c|c|c|c|}
\hline $\begin{array}{l}\text { Public places } \\
\text { sampled }\end{array}$ & Location & Smoking policy & $\begin{array}{l}\text { Sampling } \\
\text { time }\end{array}$ \\
\hline Airport & $\begin{array}{l}\text { Luggage claim } \\
\text { Main Hall } \\
\text { Waiting room } \\
\text { Cafeteria }\end{array}$ & $\begin{array}{l}\text { Prohibited } \\
\text { Prohibited } \\
\text { Prohibited } \\
\text { Allowed (except in } \\
\text { Italy and Sweden) }\end{array}$ & 14 days \\
\hline Train station & $\begin{array}{l}\text { Waiting room } \\
\text { Platform } \\
\text { Cafeteria }\end{array}$ & $\begin{array}{l}\text { Prohibited } \\
\text { Prohibited } \\
\text { Allowed (except in } \\
\text { Italy and Sweden) }\end{array}$ & 14 days \\
\hline Hospital & $\begin{array}{l}\text { Waiting room } \\
\text { Cafeteria }\end{array}$ & $\begin{array}{l}\text { Prohibited } \\
\text { Allowed (except in } \\
\text { Italy and Sweden) }\end{array}$ & 7 days \\
\hline $\begin{array}{l}\text { Restaurant } \\
\text { Schools }\end{array}$ & $\begin{array}{l}\text { Dining area } \\
\text { Corridor } \\
\text { Teacher room }\end{array}$ & $\begin{array}{l}\text { Separated } \\
\text { Prohibited } \\
\text { Allowed }\end{array}$ & $\begin{array}{l}2 \text { days } \\
7 \text { days }\end{array}$ \\
\hline University & $\begin{array}{l}\text { Corridor } \\
\text { Classroom } \\
\text { Leisure room } \\
\text { Cafeteria }\end{array}$ & $\begin{array}{l}\text { Prohibited } \\
\text { Prohibited } \\
\text { Allowed } \\
\text { Allowed }\end{array}$ & 7 days \\
\hline Disco & Personal sample & Allowed & 4 hours \\
\hline
\end{tabular}


every country (except in Spain where two train stations were sampled), and a minimum of two settings were sampled in the rest of the public places. The samplers were placed in areas of common use. In places with areas where smoking was prohibited and areas where smoking was allowed, samples were placed in both smoking and non-smoking areas. Table 1 lists the places sampled, approximate sampling time, and smoking policy.

Placement of samplers was done according to the following instructions: samplers had to hang freely in the air, not to be placed within $1 \mathrm{~m}$ of an area where someone regularly smokes, where air does not circulate such as a corner, or
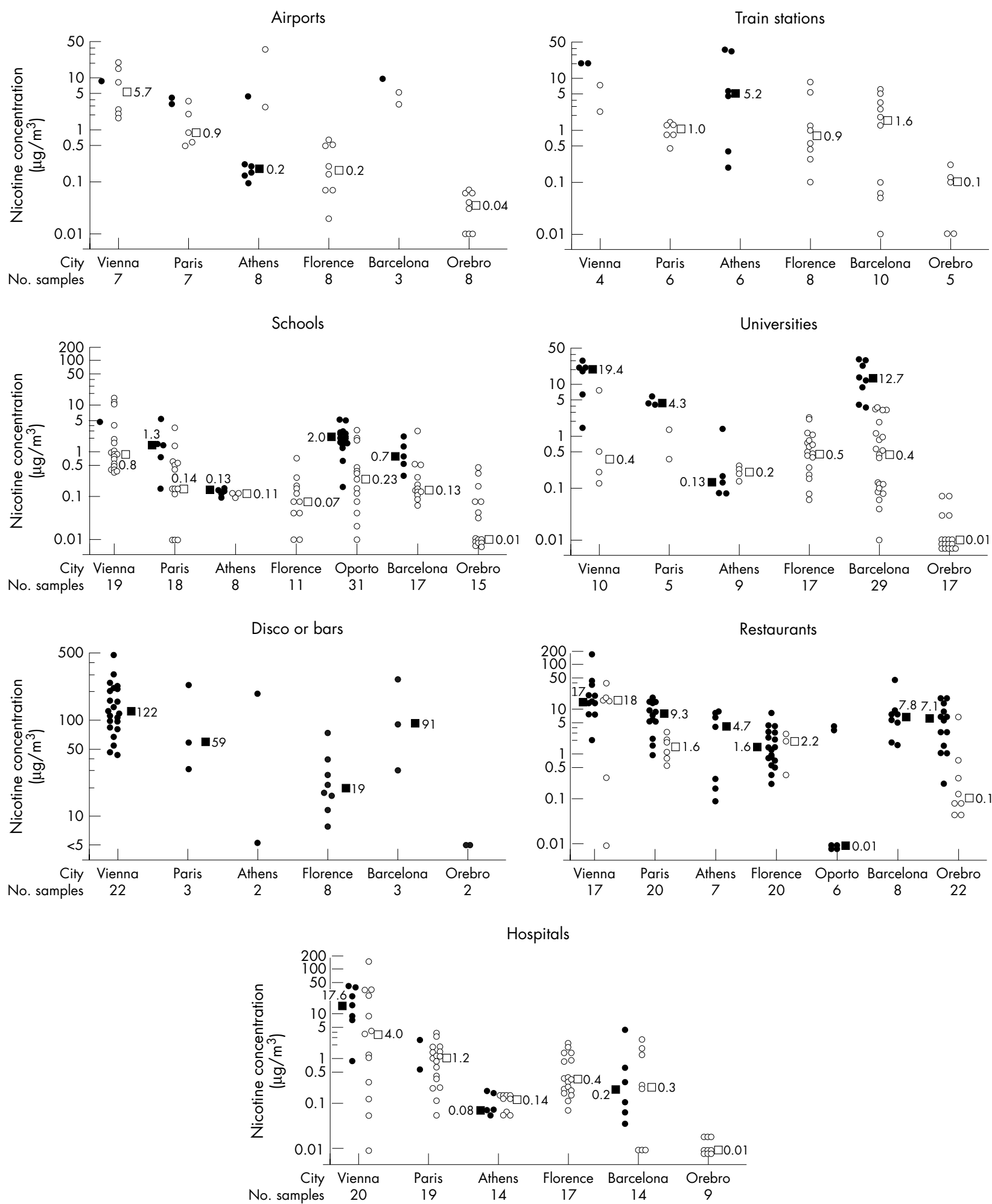

Figure 1 Concentrations of nicotine by setting and city (ETS measurement in a sample of European cities project). Solid circles: places where smoking is allowed (or there are no specified policies); solid squares represent the median concentration. Open circles: places where smoking is prohibited; open squares represent the median concentration. 
under a shelf, or buried in curtains. For personal samples, the sampler had to be clipped to a shirt collar or lapel, with the windscreen facing out, away from the clothes. For each sample the following data were recorded: country, sample's code, public place, sample location, date placed and removed, sampling area, sampling volume, and ventilation. The filters were analysed at the Laboratory of the Public Health Agency of Barcelona, by gas chromatography (GC/MS) method. The lower limit of detection is $0.01 \mu \mathrm{g} / \mathrm{ml}$. The nicotine concentration $\left(\mu \mathrm{g} / \mathrm{m}^{3}\right)$ was obtained by dividing the observed nicotine concentration by the flow rate $(24 \mathrm{ml} / \mathrm{min}$ for passive sampling) and allowing for the time the filter had been exposed. The method has been previously validated by Hammond et al, ${ }^{24}$ and used in several studies. ${ }^{1-13} 25$

\section{RESULTS}

Figure 1 shows the nicotine concentrations found in areas where smoking is and is not allowed, and the median concentrations. Bars and discos are the places with the highest concentrations, as expected, though in Orebro (Sweden) the concentrations were lower than anywhere else $\left(<5 \mu \mathrm{g} / \mathrm{m}^{3}\right)$. Generally, the nicotine concentration ranged from 10-500 $\mu \mathrm{g} /$ $\mathrm{m}^{3}$. None of the places sampled had areas where smoking was prohibited. Restaurants had the next highest concentrations. It is worth noting that in Vienna, Paris, and Florence the concentrations in parts of the restaurant where smoking was not allowed were not dissimilar to concentrations in areas where smoking was allowed. In train stations and airports most of the areas sampled had smoking restrictions, but despite this there were appreciable concentrations of nicotine, generally ranging from $0.1-5 \mu \mathrm{g} / \mathrm{m}^{3}$ in airports and $0.5-10 \mu \mathrm{g} / \mathrm{m}^{3}$ in train stations. Nicotine was also found in schools and universities, particularly in Barcelona, and again the concentrations in non-smoking areas were somewhat similar to those in areas where smoking was allowed. Schools tended to have the lowest concentrations compared to all the other public places sampled. Low concentrations were found in hospitals, though in Vienna there were areas ("smoking rooms") where the nicotine concentration was high. Generally, concentrations were below $5 \mu \mathrm{g} / \mathrm{m}^{3}$.

\section{DISCUSSION}

Although there is some variability between cities, this study shows that tobacco smoke is present in most public places. The study also showed that in areas where smoking is prohibited, concentrations of nicotine are lower than in areas where smoking is allowed but they are not zero; evidence of tobacco smoke could still be found. This suggests that policies of having separate smoking and non-smoking areas are not completely effective.

This study has some limitations regarding the sampling, such as the different number of samples taken and the differences in the placement of the samplers, which may result in differences between countries unrelated to actual exposure. The values obtained in our study include some very high levels of ETS exposure in Austria, where the sampling strategy attempted to include places where ETS exposure might be problematic. Nevertheless the results obtained give us an objective description of the levels of ETS exposure which can be used in future representative studies for selection of settings where ETS pollution is a health hazard at present.

The nicotine concentrations found in bars and discos are very high. A person dancing for four hours in a disco with the median concentration found in countries like Vienna or Barcelona is exposed to a similar amount of tobacco smoke as someone living with a smoker for a month $\left(2.2 \mu \mathrm{g} / \mathrm{m}^{3}\right) .{ }^{11}$ In fact, the values found in these countries $\left(122 \mu \mathrm{g} / \mathrm{m}^{3}\right.$ in Austria and $91 \mu \mathrm{g} / \mathrm{m}^{3}$ in Spain) translate (using the formula of Repace and Lowrey ${ }^{15}$ ) into an estimated lifetime excess lung cancer mortality risk for bar workers of 16 per 1000 and

\section{What this paper adds}

Environmental tobacco smoke (ETS) has been shown to have important health effects. However, there are not many studies showing objective data about the exposure in public places in Europe. The results found in this study provide objective data about the levels of ETS exposure in public places from seven European cities.

12 per 1000, respectively, assuming an average 40 year working lifetime. Studies in the USA have also shown that bars and clubs are associated with high ETS exposure, with concentrations ranging from $6-82 \mu \mathrm{g} / \mathrm{m}^{3}{ }^{11}$

The nicotine concentrations found in the restaurants in our study were similar to those found in US restaurants, ${ }^{13}$ where the concentrations ranged from less than $1 \mu \mathrm{g} / \mathrm{m}^{3}$ to over $20 \mu \mathrm{g} / \mathrm{m}^{3}$. Two US studies showed an average concentration of $15 \mu \mathrm{g} / \mathrm{m}^{3}{ }^{11}$ (five restaurants) and $10.5 \mu \mathrm{g} / \mathrm{m}^{3}{ }^{11}$ (33 restaurants). In another study ${ }^{26}$ based on 21 restaurants, concentrations ranged from $0.3-24.0 \mu \mathrm{g} / \mathrm{m}^{3}$. Our results are also similar to restaurants in $\mathrm{Japan}^{27}$ and Hong Kong (Oldaker et al, 1991, personal communication).

Overall, in our study $22 \%$ of the samples had nicotine concentrations greater than $6.8 \mu \mathrm{g} / \mathrm{m}^{3}$; concentrations associated with a lung cancer risk of one in 1000 assuming 45 years of working life, this is equivalent to the "significant harm" action level defined by the US Occupational Safety and Health administration. ${ }^{12}$ Repace and Lowrey ${ }^{15}$ evaluated the risk of ETS exposure in the workplace and estimated that workplace nicotine exposure of $2.3 \mu \mathrm{g} / \mathrm{m}^{3}$ for 40 years presents a lung cancer risk of three in $10000 ; 35 \%$ of the samples in our study are higher than $2.3 \mu \mathrm{g} / \mathrm{m}^{3}$. The World Health Organization declared that there is no evidence for a safe ETS exposure level ${ }^{28}$ and our study shows that in many public places there are measurable levels of ETS exposure. The results of this study indicate that well implemented smoke-free policies are necessary to eliminate exposure to tobacco smoke in public areas.

\section{ACKNOWLEDGEMENTS}

This project received financial support from the European Commission in the framework of the "Europe Against Cancer" programme as part of the ENSP Framework Project application nS12.324433 (2001 CVG2008). Neither the European Commission nor any person acting on its behalf is liable for any use made of this information.

\section{Authors' affiliations}

M Nebot, M J López, Public Health Agency, Barcelona, Spain

G Gorini, M C Fondelli, Environmental and Occupational Epidemiology Unit Center for Onchologic Study and Prevention, Tuscany Region Research Institute, Italy

M Neuberger, H Moshammer, Institut of Environmental Health, University of Vienna, Austria

S Axelsson, Orebro University Hospital, Sweden

M Pilali, M Georgouli, Hellenic Cancer Society, Athens, Greece

C Fonseca, Portuguese League Against Cancer, Portugal

K Abdennbi, Office Française le prevention du tabagisme, Paris, France A Hackshaw, St Batholomew Hospital, The London School of Medicine, London, UK

A M Laurent, Laboratoire d'Hygiène de la Ville de Paris, France J Salles, E Serrahima, F Centrich, Laboratory of the Public Health Agency, Barcelona, Spain

S K Hammond, School of Public Health, University of California, USA

\section{REFERENCES}

1 International Agency for Research on Cancer. Tobacco smoke and involuntary smoking, IARC Monographs, June, 2002;83.

2 National Cancer Institutes. Health effects of exposure to environmental tobacco smoke, Report of the California Environmental Protection Agency. Monograph 10, 1999. 
3 Hackshaw A, Law M, Wald N. The accumulated evidence on lung cancer and environmental tobacco smoke. BMJ 1997;315:7114.

4 Thun M, Henley J, Apicella L. Epidemiologic studies of fatal and nonfatal cardiovascular disease and ETS exposure from spousal smoking. Environ Health Perspect 1999;107(suppl 6):841-6.

5 Jaakkola M, Samet J. Occupational exposure to environmental tobacco smoke and health risk assessment. Environ Health Perspect 1999;107/suppl 6):829-35.

6 Howard G, Wagenknecht L. Environmental tobacco smoke and measures of subclinical vascular disease. Environ Health Perspect 1999;107/suppl 6):837-40.

7 Jaakkola $M$, Samet J. Workshop on health risks attributable to ETS exposure in the workplace. Environ Health Perspect 1999;107(suppl 6):823-8.

8 Law M, Morris J, Wald N. Environmental tobacco smoke exposure and aschaemic heart disease: an evaluation of the evidence. BMJ 1997;315:7114.

9 Weiss S, Utell M, Samet J. Environmental tobacco smoke exposure and asthma in adults. Environ Health Perspect 1999;107(suppl 6):891-5.

10 Howard G, Thun M. Why is Environmental tobacco Smoke more strongly Associated with coronary heart disease than expected? A review of potentia biases and experimental data. Environ Health Perspect 1999;107/suppl 6):835-8

11 Hammond K. Evaluating exposure to environmental tobacco smoke. In: Winegar E, Keith L, eds. Sampling and analysis of airborne pollutants. Lewis Publishers, 1993.

12 Hammond SK, Sorensens G, Youngstrom R, et al. Occupational exposure to environmental tobacco smoke. JAMA 1995;274:956-60.

13 Hammond SK. Exposure of U.S. workers to environmental tobacco smoke. Environ Health Perspect 1999:107(suppl 2):329-40.

14 Jenkins RA, Counts SW. Occupational exposure to environmental tobacco smoke: results of two personal exposure studies. Environ Health Perspect 1999; 107(suppl 2):341-8.

15 Repace JL, Lowrey AH. An enforceable indoor air quality standard for environmental tobacco smoke in the workplace. Risk Analysis 1993; 13:463-75.

16 Repace JL, Jinot J, Bayard S, et al. Air nicotine and saliva cotinine as indicators of workplace passive smoking exposure and risk. Risk Analysis 1998;18:71-83.
17 Phillips K, Howard D, Browne D, et al. Assessment of personal exposure to environmental tobacco smoke in British nonsmokers. Environ Int 1994;20:693-712

18 Phillips K, Bentley M, Howard D, et al. Assessment of air quality in Stockholm by personal monitoring of nonsmokers for respirable suspended particles and environmental tobacco smoke. Scand J Work Environ Health 1996;22(suppl 1): $1-24$

19 Phillips K, Bentley M, Howard D, et al. Assessment of air quality in Barcelona by personal monitoring of nonsmokers for respirable suspended particles and environmental tobacco smoke. Environ Int 1997;23:173-96.

20 Phillips K, Howard D, Bentley M, et al. Assessment of air quality in Turin by personal monitoring of nonsmokers for respirable suspended particles and environmental tobacco smoke. Environ Int 1997;23:851-71.

21 Phillips K, Bentley M, Howard D, et al. Assessment of air quality in Paris by personal monitoring of nonsmokers for respirable suspended particles and environmental tobacco smoke. Environ Int 1998;24:405-25.

22 Phillips K, Howard D, Bentley M, et al. Assessment of environmental tobacco smoke and respirable suspended particle exposures for nonsmokers in Lisboa by personal monitoring. Environ Int 1998;24:301-24.

23 Ong EK, Glantz SA. Tobacco industry efforts subverting International Agency for Research on Cancer's second-hand smoke study. Lancet 2000;355:1253-9.

24 Hammond K, Leaderer B, Roche A, et al. Collection and analysis of nicotine as a marker for environmental tobacco smoke. Atmospheric Environment 1987:21:457-62

25 Jané $M$, Nebot $M$, Rojano $X$, et al. Exposure to environmental tobacco smoke in several public places of Barcelona. Tobacco Control 2002;1 1:83-4.

26 Crouse WE, Oldaker GB. Comparison of area and personals sampling methods for determining nicotine in environmental tobacco smoke. Proceedings of the 1990 EPA/AWMA International Symposium of Toxic and Related Air Pollutant, Raleigh, North Carolina, 1990:562-6.

27 Muramatsu M, Umemura S, Okada T, et al. Estimation of personal exposure to tobacco smoke with a newly developed nicotine personal monitor. Environ Res 1984;35:218-27.

28 World Health Organization. Air quality guidelines, 2nd ed.WHO Regional Publications, European Series, No.91.WHO, Regional Office for Europe, 2000

\section{The Lighter Side}

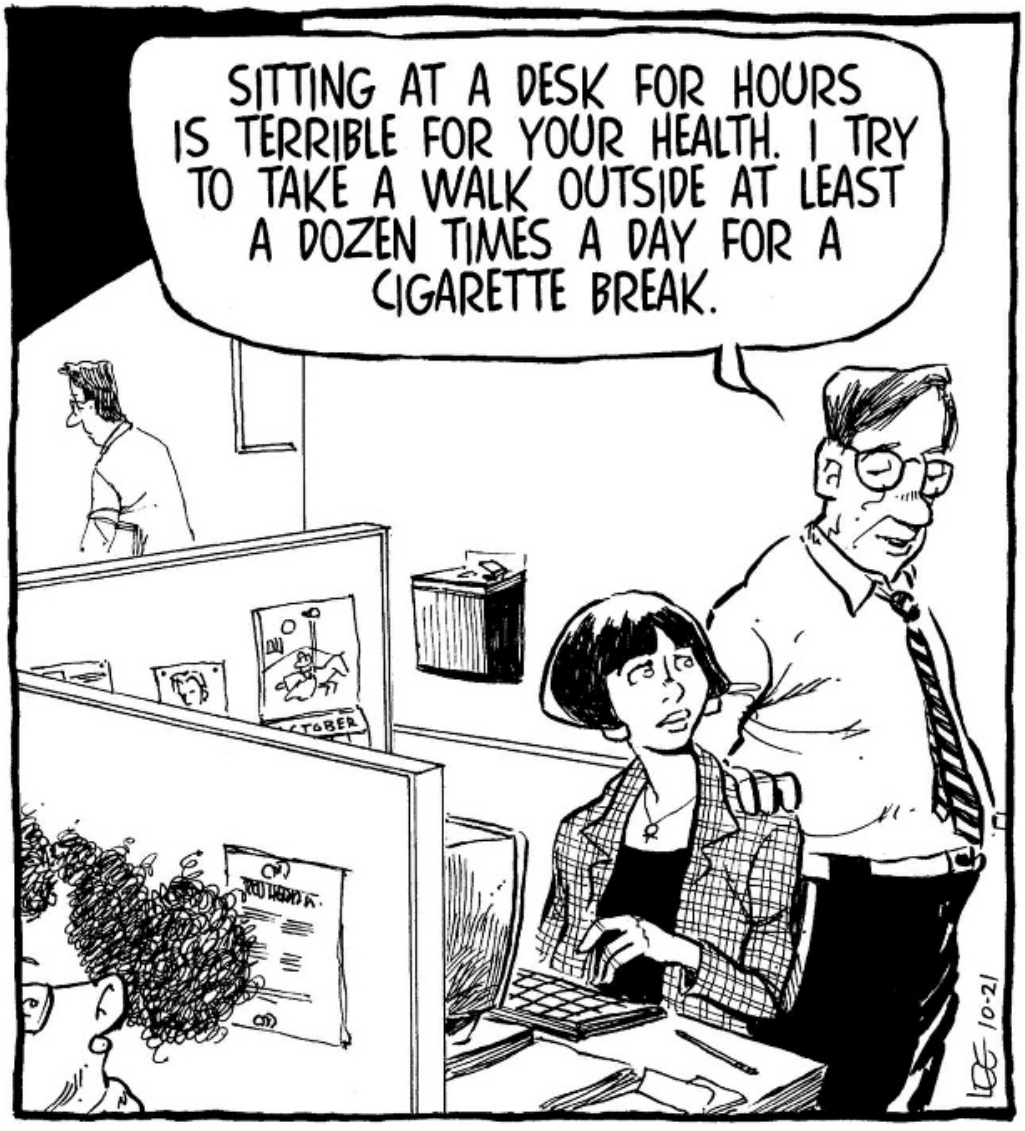

(C) Pardon My Planet by Vic Lee. King Features Syndicate. Reprinted with permission Torstar Syndication Services. 